\title{
Almond Shell-Derived, Biochar-Supported, Nano-Zero-Valent Iron Composite for Aqueous Hexavalent Chromium Removal: Performance and Mechanisms
}

\author{
Yaorong Shu ${ }^{1}$, Bin $\mathrm{Ji}^{1,2,3}$, Baihui Cui ${ }^{4}$, Yuting Shi ${ }^{1}$, Jian Wang ${ }^{1}$, Mian $\mathrm{Hu}^{5}$, Siyi Luo ${ }^{6}$ and \\ Dabin Guo ${ }^{1,7, *}$ \\ 1 School of Urban Construction, Wuhan University of Science and Technology, Wuhan 430065, China; \\ yaorongshuwust@126.com (Y.S.); binji@wust.edu.cn (B.J.); yutingshiwust@126.com (Y.S.); \\ okwj@wust.edu.cn (J.W.) \\ 2 Guangdong Institute of Resources Comprehensive Utilization, Guangzhou 510650, China \\ 3 Guangdong Provincial Key Laboratory of Development and Comprehensive Utilization of Mineral \\ Resources, Guangzhou 510650, China \\ 4 Institute of Hydrobiology, Chinese Academy of Sciences, Wuhan 430072, China; cuibaihui@ihb.ac.cn \\ 5 College of Environment, Zhejiang University of Technology, Hanzhoug 310014, China; mianhu@zjut.edu.cn \\ 6 School of Environmental and Municipal Engineering, Qingdao University of Technology, Qingdao 266033, \\ China; luosiyi666@126.com \\ 7 School of Environmental Science and Engineering, Huazhong University of Science and Technology, \\ Wuhan 430074, China \\ * Correspondence: dabin@hust.edu.com
}

Received: 14 December 2019; Accepted: 21 January 2020; Published: 23 January 2020

\begin{abstract}
Nano-zero-valent iron biochar derived from almond shell (nZVI-ASBC) was used for hexavalent chromium (CR) removal. Experiments showed that $\mathrm{pH}$ was the main factor $(p<0.01)$ that affected the experimental results. At a dosage of $10 \mathrm{mg} \cdot \mathrm{L}^{-1}$ and $\mathrm{pH}$ of $2-6$, in the first $60 \mathrm{~min}$, nZVI-ASBC exhibited a removal efficiency of $99.8 \%$, which was approximately $20 \%$ higher than the removal yield at $\mathrm{pH}$ 7-11. Fourier transform infrared spectroscopy results indicated N-H was the main functional group that influenced the chemisorption process. The pseudo second-order dynamics and Langmuir isotherm models proved to be the most suitable. Thermodynamic studies showed that the reaction was exothermic and spontaneous at low temperatures $(\mathrm{T}<317 \mathrm{~K})$. Various interaction mechanisms, including adsorption and reduction, were adopted for the removal of $\mathrm{Cr}(\mathrm{VI})$ using the nZVI-ASBC composite. The findings showed that the BC-modified nZVI prepared with almond shell exerts a good effect and could be used for the removal of $\mathrm{Cr}(\mathrm{VI})$.
\end{abstract}

Keywords: biochar; nzvi; Cr(VI); orthogonal experiment; adsorption

\section{Introduction}

As industrialization proceeds, water pollution continues to elicit much attention. Hexavalent chromium $[\mathrm{Cr}(\mathrm{VI})]$ is a typical toxic heavy metal contaminant produced mainly from industrial processes, such as steel fabrication, metal processing, tanning, dyeing, leather, and paint manufacturing [1]. Chromium has been associated with lung cancer, dermatitis, skin irritation, and other diseases and is classified as a hazardous substance [2].

Many physicochemical methods can be used to remove $\mathrm{Cr}(\mathrm{VI})$, and biochar may be promoted as a tool for reducing and removing bioavailable heavy metal from contaminated waters and soils [3-5]. As a pyrogenic carbon, biochar (BC) is derived from carbon-rich waste materials. Almond shells are 
nut product residues that are usually discarded and incinerated, which pollutes the environment and wastes resources. Similar to BC, almond shells have pores. Almond has a large pore diameter of 300-500 $\mu \mathrm{m}$ and a small pore diameter of 40-60 $\mu \mathrm{m}$ [6]. Therefore, almond shell is considered a good material for burning to prepare BC.

Many researchers have studied the application of nano-zero-valent iron (nZVI) and its modified products in wastewater treatment [7]. nZVI has a large specific surface area and small particle size, which prove to be beneficial for removing heavy metals [8,9]. Dalal and Reddy showed that $\mathrm{Cr}(\mathrm{VI}) \mathrm{can}$ be removed by nZVI [10]. However, nZVI is unpredictably oxidized and agglomerated. Many methods for improving nZVI, such as bimetals and different types of carriers, have been developed to address these disadvantages [11]. nZVI has been modified into $\mathrm{Fe} / \mathrm{Ni}$ or $\mathrm{Fe} / \mathrm{Cu}$ bimetal to reduce the oxidation of nZVI [9,12,13]. Wang et al. [14] used blended membranes of boehmite-PVB/PVDF as a carrier to prevent the agglomeration of nZVI. Qian et al. [15] found BC synthesized from corn stalk could be used as a carrier of nZVI and to reduce agglomeration, which showed that metals can be removed by this modified nZVI.

In this study, we used BC made from almond shells as the carrier of nZVI. Almond shells are directly discarded as garbage. This waste was collected and processed to create valuable BC, which was then used as a carrier for nZVI to prepare nZVI loaded on almond BC (nZVI-ASBC). Then, we analyzed the mechanism of Cr removal by nZVI-ASBC in detail. An orthogonal experiment showed that the main factors that influenced the removal effect were the initial concentration of $\mathrm{Cr}(\mathrm{VI})$ and $\mathrm{pH}$. The effects of the $\mathrm{pH}$ and initial concentration of $\mathrm{Cr}(\mathrm{VI})$ on the removal of $\mathrm{Cr}(\mathrm{VI})$ were studied in detail. To investigate the removal mechanism, we characterized the material through different methods and instruments. We performed scanning electron microscopy (SEM) and energy dispersive spectrometry (EDS) to analyze the surface morphology and composition of the material, respectively. The state of the material before and after the reaction was analyzed through X-ray diffraction (XRD) and X-ray photoelectron spectroscopy (XPS). Fourier transform infrared spectroscopy (FTIR) was implemented to analyze the functional groups that attached to the surface of BC before and after the reaction.

\section{Materials and Methods}

\subsection{Material Preparation}

All chemicals and reagents utilized in this study were of analytical grade. The almond shells were obtained from food residue. The almond shells were washed three times and placed in an oven for drying. The dried almond shells were then placed in a crucible and pyrolyzed in a muffle furnace, which was heated from room temperature to $600{ }^{\circ} \mathrm{C}$ at a rate of $3{ }^{\circ} \mathrm{C} \cdot \mathrm{min}^{-1}$, and maintained in the oxygen-limited condition (without any gas circulation) for $2 \mathrm{~h}$. The prepared BC was washed three times with distilled water. The washed BC was suction filtered with a $0.45-\mu \mathrm{m}$ filter membrane. And the $\mathrm{BC}$ was baked in an oven to a constant weight at $100{ }^{\circ} \mathrm{C}$ and stored in a sealed bag afterward.

nZVI-ASBC was synthesized through the liquid phase reduction method. Under nitrogen, $0.2 \mathrm{M}$ of $\mathrm{NaBH}_{4}$ solution was added after adding $\mathrm{FeSO}_{4} \cdot 7 \mathrm{H}_{2} \mathrm{O}$ with a concentration of $0.15 \mathrm{M}$ to a $250-\mathrm{mL}$ three-necked flask. Then, the solution was stirred at $300 \mathrm{rpm}$ to complete the reaction. Subsequently, $2.51 \mathrm{~g}$ of powdered BC passing through a 100-mesh screen was added to the three-necked flask before the $\mathrm{NaBH}_{4}$ solution was added dropwise. The process lasted for about an hour. nZVI-ASBC was eventually separated using a vacuum suction bottle, washed with alcohol, dried, and stored in a sealed bag filled with $\mathrm{N}_{2}$ to avoid oxidation.

\subsection{Orthogonal Experimental Design and Statistical Analysis}

An orthogonal experiment was designed to determine the influence degree of each factor. The orthogonal experiment, L25 $\left(1^{5} \times 1^{4} \times 1^{5}\right)$, involved three factors, namely, the temperature, $\mathrm{pH}$, and initial concentration of $\mathrm{Cr}(\mathrm{VI})$. The temperature included three parallels $(283,288,293,298$, and $303 \mathrm{~K})$, $\mathrm{pH}$ included five parallels $(\mathrm{pH}=3,5,7,9,11)$, and the initial concentration of $\mathrm{Cr}(\mathrm{VI})$ included four 
parallels $\left(10,20,30\right.$, and $\left.40 \mathrm{mg} \cdot \mathrm{L}^{-1}\right)$. SPSS software was used to design and analyze the orthogonal experiments. The orthogonal experiments were performed, and the experimental results were imported into SPSS. We used the $p$ value to determine the impact of various factors on the experiments. Generally, when the $p$ value is $0.01<p<0.05$, the difference is significant. When $p \leq 0.01$, the difference is extremely significant. If $p \geq 0.05$, the difference is not significant.

\section{3. $\mathrm{Cr}(V I)$ Removal Experiment and Analysis}

In accordance with the results of the orthogonal experiments, the $\mathrm{pH}$ and the initial concentration of $\mathrm{Cr}(\mathrm{VI})$ were tested in turn. When exploring the effects of $\mathrm{pH}$ on the experiments, $\mathrm{Cr}(\mathrm{VI})$ was removed by varying the solution $\mathrm{pH}$ from 2 to 11 . When studying the effect of the initial concentration of $\mathrm{Cr}(\mathrm{VI})$ on the experiments, we tested the initial concentration of $\mathrm{Cr}(\mathrm{VI})$ from 0 to $90 \mathrm{mg} \cdot \mathrm{L}^{-1}$. The $\mathrm{Cr}(\mathrm{VI})$ wastewater prepared in the experiment is a simulated underground wastewater. During the experiment, $0.08 \mathrm{~g}$ of $\mathrm{nZVI}-\mathrm{ASBC}$ were added to each reaction, and the conical flask containing the solution was placed on a constant temperature shaker at a speed of $150 \mathrm{rpm}$. At the end of the reaction, $1 \mathrm{~mL}$ of the solution was injected into a colorimetric tube through a $0.45-\mu \mathrm{m}$ filter. Then, $1 \mathrm{~mL}$ of the filtered solution was placed into a 50-mL colorimetric tube and diluted to the mark with distilled water. After, $4 \mathrm{~mL}$ of diphenylcarbazide were added to the colorimeter tube and mixed for $5 \mathrm{~min}$, and $1 \mathrm{~mL}$ of sulfuric acid $(1+1)$ was added to the colorimeter tube and mixed for 5-10 min. Spectrophotometry was performed to determine the concentration of $\mathrm{Cr}(\mathrm{VI})$. The removal efficiency $(\eta, \%)$ and unit removal capacity $\left(\mathrm{Q}_{\mathrm{e}}, \mathrm{mg} \cdot \mathrm{g}^{-1}\right)$ were calculated using Equations (1) and (2), respectively:

$$
\begin{gathered}
\eta=\frac{C_{0}-C_{e}}{C_{0}} \times 100 \%, \\
Q_{e}=\frac{V\left(C_{0}-C_{e}\right)}{M},
\end{gathered}
$$

where $\mathrm{C}_{0}$ and $\mathrm{C}_{\mathrm{e}}$ are the initial and equilibrium concentrations of $\mathrm{Cr}$, respectively; $\mathrm{V}$ is the solution volume (L); and $\mathrm{M}$ is the mass of the adsorbent (g). XRD, XPS, SEM, EDS, and FTIR were conducted for characterization.

\section{Results and Discussion}

\subsection{Orthogonal Experimental Analysis}

The degree of effect of each factor was determined through an orthogonal experiment, which revealed that $\mathrm{pH}$ was the main factor that influenced the experiment. The $p$ value of $\mathrm{pH}(p=0.004)$ was the lowest and lower than 0.05 , indicating that $\mathrm{pH}$ had the most significant impact on this experiment. The $p$ value of the initial concentration of $\operatorname{Cr}(\mathrm{VI})(p=0.015)$ was between 0.01 and 0.05 , indicating that the experimental results were affected by the initial concentration of $\mathrm{Cr}(\mathrm{VI})$. However, the influence was less than that of $\mathrm{pH}$. The $p$ value of the temperature was 0.041 , indicating that temperature has a great influence on the occurrence of the reaction. However, the temperature's influence is not as strong as the $\mathrm{pH}$ and initial of concentration of $\mathrm{Cr}(\mathrm{VI})$. From the results of the ANOVA analysis, we can find that the $p$ values of the above three are all less than 0.05 . Therefore, a specific experiment was performed for these three factors.

\subsection{Effect of Initial $\mathrm{pH}$}

Figure 1a shows that the removal of $\mathrm{Cr}(\mathrm{VI})$ is not conducive to high $\mathrm{pH}$ environments. By contrast, the removal of $\mathrm{Cr}(\mathrm{VI})$ can be enhanced in an acidic environment. To study the effect of $\mathrm{pH}$ on the removal of $\mathrm{Cr}$ by $\mathrm{nZVI-ASBC}$, $\mathrm{pH}$ was varied from 2 to 11 in the $\mathrm{Cr}$ removal experiment, in which the concentration of $\mathrm{Cr}(\mathrm{VI})$ was $10 \mathrm{mg} \cdot \mathrm{L}^{-1}$. Figure 1 a shows that the removal yield of $\mathrm{Cr}$ was approximately $90 \%$ within $60 \mathrm{~min}$. The Cr(VI) solution could be adsorbed by nZVI-ASBC to achieve a maximum removal yield of $\mathrm{pH}=2$ to $6(99.80 \%)$, which was $20 \%$ higher than that of $\mathrm{pH} 7$ to 11 in $60 \mathrm{~min}$. 
This conclusion is similar to that of Wu et al. [16]. Although the same high removal yield of the acidic solution could be achieved by the $\mathrm{Cr}(\mathrm{VI})$ solution with $\mathrm{pH}$ between 7 and 11, the maximum removal yield could only be achieved when the time reached $210 \mathrm{~min}$.
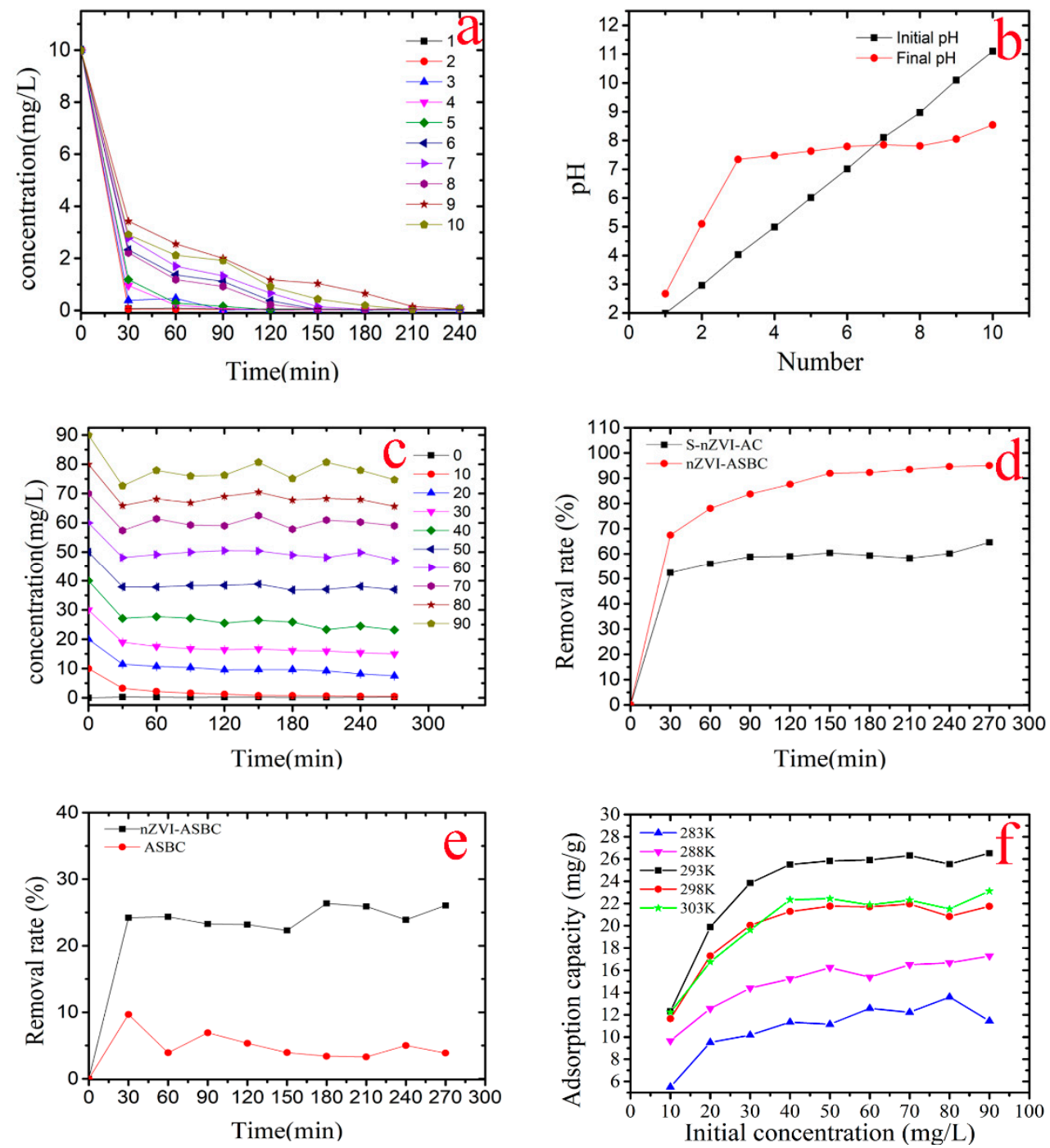

Figure 1. (a,c) are the effects of the $\mathrm{pH}$ and initial concentration of $\mathrm{Cr}(\mathrm{VI})$ on the removal of $\mathrm{Cr}$ by nZVI-ASBC, respectively. (b) shows the change in $\mathrm{pH}$ before and after the reaction. (d,e) are comparisons of the ASBC, S-nZVI-AS, and nZVI-ASBC removal rates. (f) is a comparison of the adsorption capacity at different temperatures.

As shown in Figure 1b, each pH value was neutral at the end of the experiment and depended mainly on the different forms of existing $\mathrm{Cr}(\mathrm{VI})$. $\mathrm{Cr}$ was presented in a form of chromic acid $\left(\mathrm{H}_{2} \mathrm{CrO}_{4}\right)$ under strong acidic $(\mathrm{pH}<1)$ conditions. $\mathrm{HCrO}_{4}{ }^{-}$appeared to be stable when $\mathrm{pH}$ was between 1 and 6. $\mathrm{Cr}(\mathrm{VI})$ existed in the form of $\mathrm{CrO}_{4}{ }^{2-}$ when $\mathrm{pH}$ was higher than 6 [17]. Various forms of $\mathrm{Cr}(\mathrm{VI})$ underwent chemical reactions at different $\mathrm{pH}$ values. Under acidic conditions, $\mathrm{Cr}(\mathrm{VI})$ was adsorbed by nZVI-ASBC and reduced to $\mathrm{Cr}$ (III) by nZVI. Meanwhile, $\mathrm{Fe}^{0}$ was oxidized to Fe (II) and Fe (III). Under alkaline conditions, $\mathrm{Cr}(\mathrm{VI})$ and iron underwent a redox reaction to form $\mathrm{Cr}$ (III) and Fe (III), which reacted with $\mathrm{OH}^{-}$to form $\mathrm{Cr}(\mathrm{OH})_{3}, \mathrm{FeOOH}$, or $\mathrm{Fe}(\mathrm{OH})_{3}$ [18]. The final $\mathrm{pH}$ decreased due to the consumption of $\mathrm{OH}^{-}$in the reaction. 


\subsection{Effect of the Initial Concentration of $\mathrm{Cr}(V I)$}

Figure $1 \mathrm{c}$ indicates that the removal yield continued to decrease as the initial concentration of $\mathrm{Cr}(\mathrm{VI})$ increased. To determine the effects of the initial concentration of $\mathrm{Cr}(\mathrm{VI})$ in detail, different initial concentrations of the $\mathrm{Cr}(\mathrm{VI})$ solution (from 0 to $90 \mathrm{mg} \cdot \mathrm{L}^{-1}$ ) were used for removal by nZVI-ASBC. Each solution concentration was added with $0.08 \mathrm{~g}$ of $\mathrm{nZVI-ASBC}$. The conditions for the reaction were of $293 \mathrm{~K}$ and $\mathrm{pH}=6$. As shown in Figure 1c, the removal efficiency of $\mathrm{Cr}(\mathrm{VI})$ by nZVI-ASBC was different at its different initial concentration of $\mathrm{Cr}(\mathrm{VI})$ in the solution. When the initial concentration of $\mathrm{Cr}(\mathrm{VI})$ was $10 \mathrm{mg} \cdot \mathrm{L}^{-1}, 95.01 \%$ of $\mathrm{Cr}(\mathrm{VI})$ was removed by nZVI-ASBC, and the removal yield was much higher than that for the initial concentration of $\mathrm{Cr}(\mathrm{VI})$ of $90 \mathrm{mg} \cdot \mathrm{L}^{-1}$ (removal yield was $66.59 \%$ ).

The removal capability and removal speed significantly improved compared with those with activated carbon as a carrier. As shown in Figure $1 d$, the removal yield of $\mathrm{Cr}(\mathrm{VI})$ by nZVI-ASBC (95.01\%) was $30.40 \%$ higher than that by starch nZVI-immobilized activated carbon (S-nZVI-AC, removal yield $=64.61 \%$ ). Figure $1 \mathrm{~d}$ clearly shows that the slope of nZVI-ASBC was significantly larger than that of S-nZVI-AC. This condition indicates that the removal yield of nZVI-ASBC is higher than that of S-nZVI-AC. Hence, nZVI-ASBC is superior to S-nZVI-AC not only in terms of removal yield but also in terms of removal speed.

Figure $1 \mathrm{f}$ illustrates that the adsorption capacity of nZVI-ASBC increased with increasing concentration when the concentration was $0-50 \mathrm{mg} \cdot \mathrm{L}^{-1}$. When the initial concentration of $\mathrm{Cr}(\mathrm{VI})$ rose to $50 \mathrm{mg} \cdot \mathrm{L}^{-1}$, the adsorption capacity stabilized because the adsorbent of this mass had reached adsorption saturation. Figure $1 \mathrm{f}$ shows that $26.63 \mathrm{mg} \cdot \mathrm{g}^{-1}$ was the saturated adsorption capacity of nZVI-ASBC at $293 \mathrm{~K}$. As the temperature rose from 283 to $303 \mathrm{~K}, 293 \mathrm{~K}\left(26.63 \mathrm{mg} \cdot \mathrm{g}^{-1}\right)$ was found to be the optimal temperature during removal. A comparison revealed that the adsorption capacity of nZVI-ASBC at $293 \mathrm{~K}$ is better than the adsorption capacity of nZVI@HCl-BC [19]. In addition, the adsorption capacity increased by $8.83 \mathrm{mg} \cdot \mathrm{g}^{-1}$, proving that $\mathrm{nZVI-ASBC}$ has a good adsorption effect and high adsorption capacity at low temperatures. The experiments also proved that $3.87 \%$ of $\mathrm{Cr}(\mathrm{VI})$ was adsorbed by the almond shell BC (Figure 1e) when the initial concentration of $\mathrm{Cr}(\mathrm{VI}) \mathrm{was}$ $50 \mathrm{mg} \cdot \mathrm{L}^{-1}$. The removal yield of simple almond $\left(26.05 \%\right.$, initial concentration of $\mathrm{Cr}(\mathrm{VI})$ of $\left.50 \mathrm{mg} \cdot \mathrm{L}^{-1}\right)$ was much lower than that of nZVI-ASBC. This result indicates that adsorption as part of the removal factor exists in the adsorption process, and cooperates with the redox reaction to remove $\mathrm{Cr}(\mathrm{VI})$.

\subsection{Physicochemical Characterization of Cr(VI) Removal by nZVI-ASBC}

\subsubsection{SEM and EDS of Cr(VI)-Fe (0) Reactions}

To investigate the removal mechanism of $\mathrm{Cr}(\mathrm{VI})$, SEM-EDS was performed for surface characterization of nZVI-ASBC. The surface morphology of nZVI-ASBC before and after the reaction is shown in Figure 2. Before the reaction, nZVI existed in a spherical shape in the pores and surfaces of BC (Figure 2a). The SEM images show that the nZVI particles were evenly distributed on the ASBC surface, although a small amount of nZVI appeared in the form of aggregates. Measurements indicated that the diameter of nZVI was approximately 50-200 nm. After the reaction, as shown in Figure $2 b$, several needle-like and layered structures, which should be Fe (III) or Cr (III) [20], appeared on the surface.

EDS was used to prove that the needles formed on the surface of BC were Fe and Cr. In Figure 2d, the mapping picture of the element clearly shows the coverage of Fe and $\mathrm{Cr}$ elements on BC. Compared with the before reaction, the $\mathrm{Cr}$ element appeared on $\mathrm{BC}$, indicating that $\mathrm{Cr}$ was adsorbed. Meanwhile, the content of each element was determined by EDS (Figure 2e,f). Compared with the pre-reaction, the content of Fe decreased after the reaction. This result is consistent with the assumptions in SEM. Although we can initially determine the elemental composition of nZVI-ASBC by SEM and EDS, we cannot obtain accurate element information. XRD and XPS were conducted for an in-depth analysis to accurately determine what complex the existing element was. 

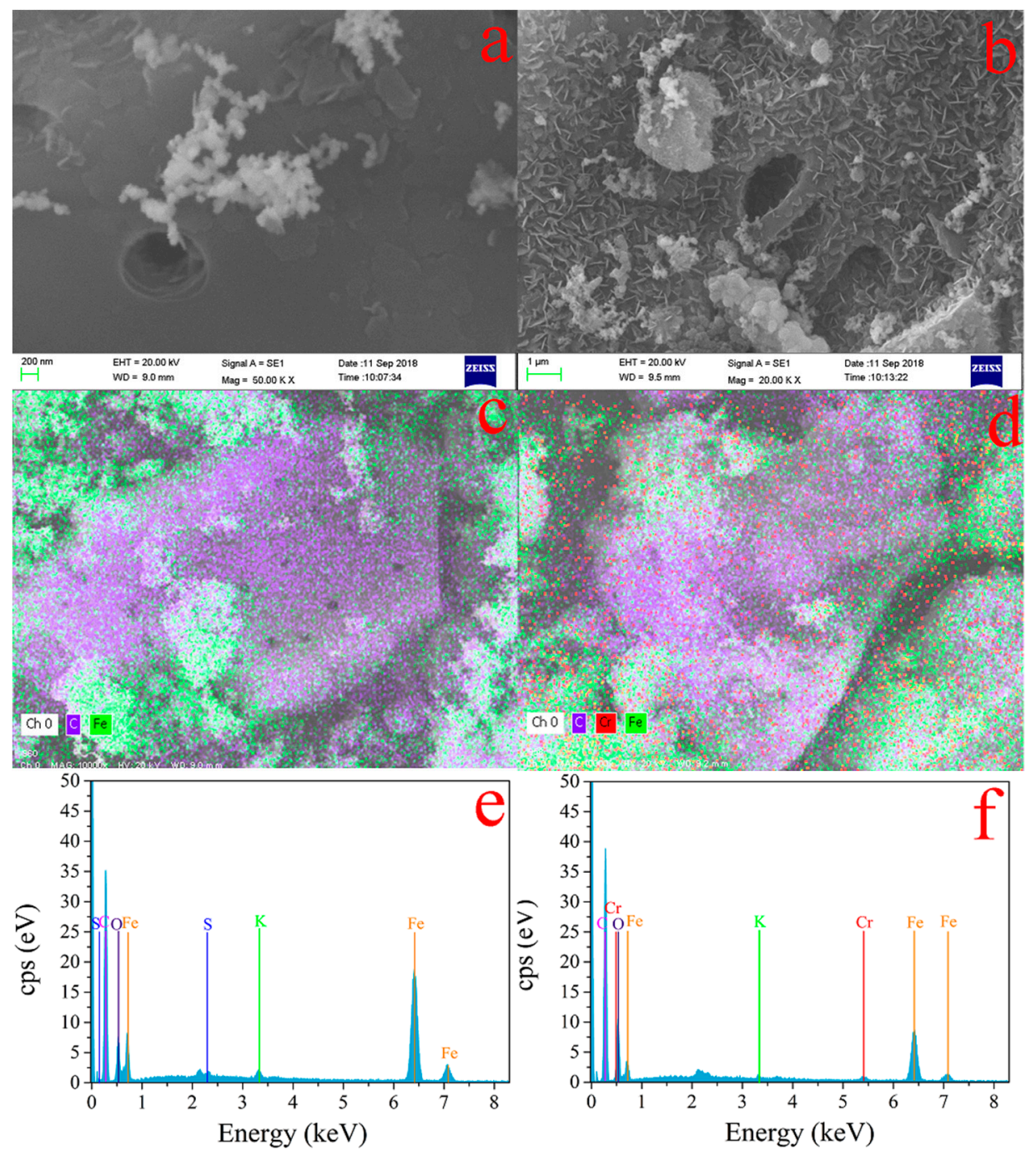

Figure 2. SEM images of nZVI-ASBC:(a) before and (b) after the reaction. Mapping images of nZVI-ASBC: (c) before and (d) after the reaction. EDS images of nZVI-ASBC: (e) before and (f) after the reaction.

\subsection{2. $\mathrm{XRD}$ and $\mathrm{XPS}$ of $\mathrm{Cr}(\mathrm{VI})-\mathrm{Fe}(0)$ Reactions}

The crystal structure of nZVI-ASBC was analyzed by XRD. Figure 3 shows a strong peak of $44.83^{\circ}$ (reference code: 00-003-1050) corresponding to the planes of iron [21]. The carbon peak was found at $2 \theta=26.3$ (reference code: 00-001-0640). These results indicate that zero-valent iron had good crystallization on the surface of BC. After the reaction, $\gamma$-FeOOH (reference code: 01-089-6096) and $\alpha-\mathrm{Fe}_{2} \mathrm{O}_{3}$ had peak values of $2 \theta=14.1^{\circ}$ and $33.1^{\circ}$, respectively, indicating that the redox reaction occurred between $\mathrm{Cr}(\mathrm{VI})$ and $\mathrm{Fe}^{0}$. 

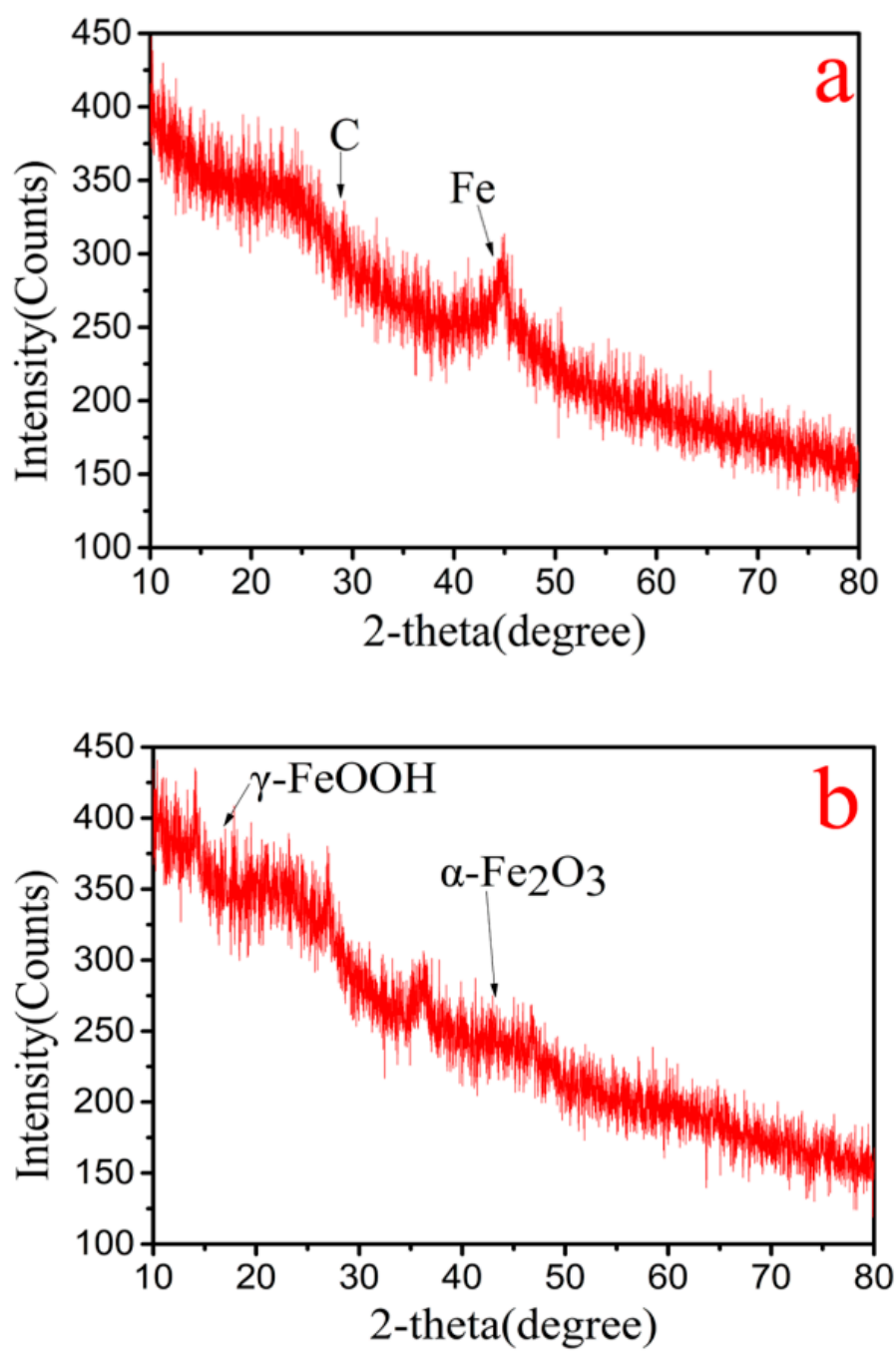

Figure 3. XRD diagrams of nZVI-ASBC:(a) XRD pattern before $\mathrm{Cr}$ was removed by nZVI-ASBC. (b) XRD pattern after Cr was removed by nZVI-ASBC.

The adsorbents before and after the reaction were characterized by XPS, which was used to analyze the detailed process of $\mathrm{Cr}(\mathrm{VI})$ reduction by nZVI-ASBC. A series of peaks, such as Fe 2p, O2s, and $\mathrm{C} 1 \mathrm{~s}$, were found on the initial adsorbent surface. The peak of $\mathrm{Cr} 2 \mathrm{p}$ appeared clearly compared with the initial adsorbent, indicating that the surface of nZVI-ASBC could adsorb $\mathrm{Cr}(\mathrm{VI})$ in the solution during the reaction. We attribute the removal of $\mathrm{Cr}$ by $\mathrm{nZVI-ASBC}$ to adsorption and redox, which is consistent with the conclusions of previous researchers [22]. With regard to the reacted $\mathrm{Cr}, \mathrm{Cr} 2 \mathrm{p}$ had two peaks at $586.5\left(\mathrm{Cr} 2 \mathrm{p}_{1 / 2}\right)$ and $577.2\left(\mathrm{Cr} 2 \mathrm{p}_{3 / 2}\right)$ eV. Figure $4 \mathrm{~d}$ shows that the broad peak of $\mathrm{Cr} 2 \mathrm{p}_{3 / 2}$ can be fitted into two peaks. The two peaks at 578.0 and $576.6 \mathrm{eV}$ are characteristic peaks of $\mathrm{Cr}(\mathrm{VI})$ and $\mathrm{Cr}$ (III), respectively. This finding indicates that $\mathrm{Cr}_{2} \mathrm{O}_{3}$ and $\mathrm{Cr}(\mathrm{OH})_{3}$ precipitated on the surface of nZVI-ASBC [23]. As shown in Figure 4, the curve has two distinct areas, namely, a high-energy zone $\left(\mathrm{Fe} 2 \mathrm{p}_{1 / 2}\right)$ and a low-energy zone $\left(\mathrm{Fe} 2 \mathrm{p}_{3 / 2}\right)$. The peak disappeared around $707.2 \mathrm{eV}(\alpha-\mathrm{Fe})$ compared with that before the reaction [24]. This phenomenon indicates that Fe underwent oxidation-reduction during the reaction, causing $\mathrm{Fe}^{0}$ to disappear. In addition to the peak around $707.2 \mathrm{eV}$, Fe also fitted the three other peaks. The three peaks at 711.2, 713.0, and $725.1 \mathrm{eV}$ were characteristic peaks of Fe. These XPS results provide conclusive evidence that redox reactions occurred in the adsorption of $\mathrm{Cr}(\mathrm{VI})$. 

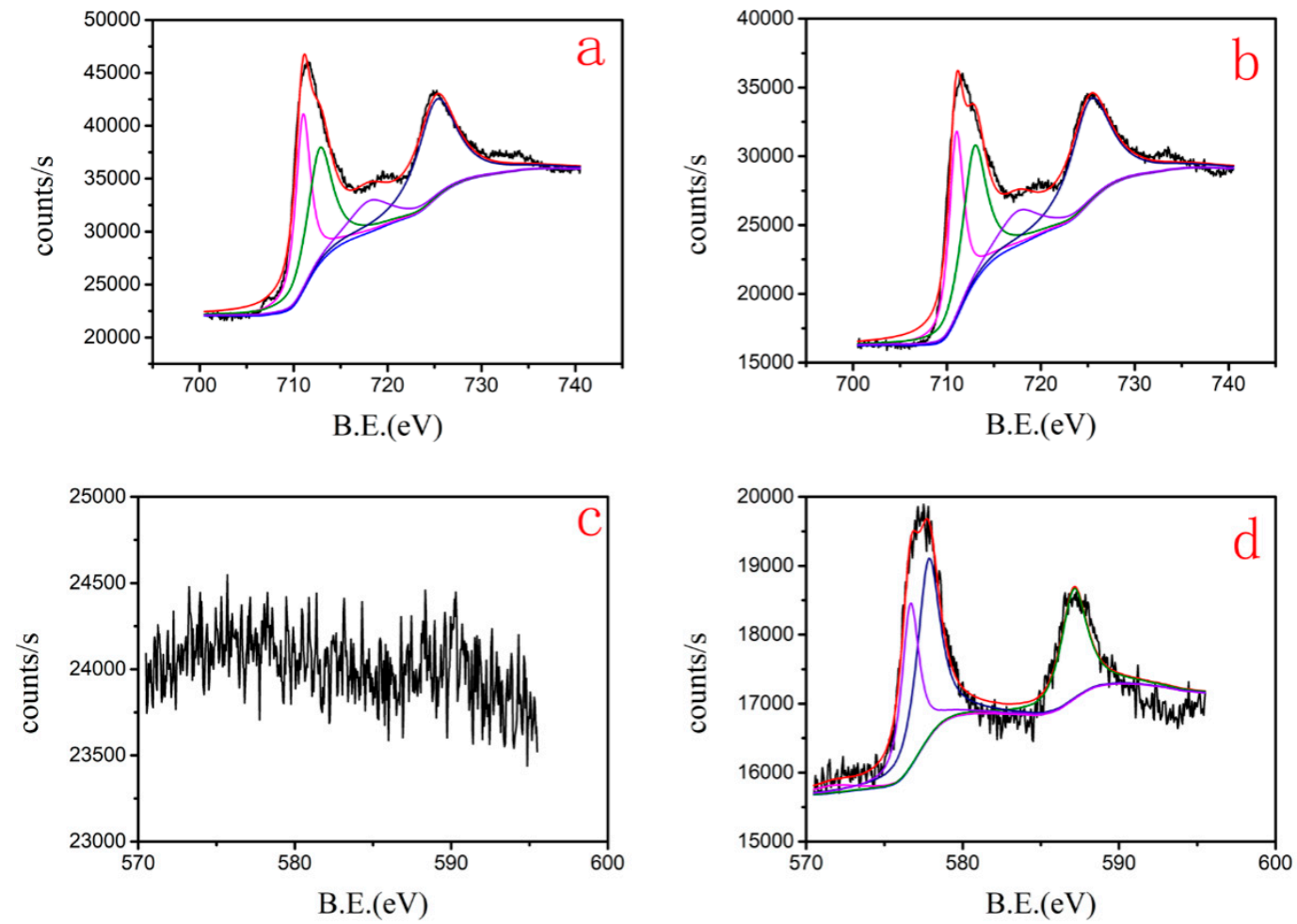

Figure 4. XPS diagrams before and after $\mathrm{Cr}$ is removed by nZVI-ASBC: $(\mathbf{a}, \mathbf{b})$ are the XPS diagrams of Fe2p before and after removal, respectively. (c,d) are the XPS diagrams of Cr2p before and after removal, respectively.

\subsubsection{FTIR of $\mathrm{Cr}(\mathrm{VI})-\mathrm{Fe}(0)$ Reactions}

The change in the surface functional groups of nZVI-ASBC was analyzed by comparing the FTIR spectra of nZVI-ASBC before and after adsorption at $\mathrm{pH}=5$. Figure 5 indicates that the vibration at a spectrum of $3420 \mathrm{~cm}^{-1}$ was a vibration of the $\mathrm{N}-\mathrm{H}$ band in ASBC [25]. The peak at $1103 \mathrm{~cm}^{-1}$ was attributed to a $\mathrm{C}-\mathrm{O}$ group of phenols. The type of bonding forming between ASBC and iron may be Fe-O-H at $670 \mathrm{~cm}^{-1}$ [26]. After $\mathrm{Cr}(\mathrm{VI})$ was adsorbed, a fresh peak at $570 \mathrm{~cm}^{-1}$ appeared on the infrared spectrum, which was considered to be the $\mathrm{Cr}=\mathrm{O}$ bond formed by the $\mathrm{Cr}$ reaction. In addition, a new sharp peak was found at $1383 \mathrm{~cm}^{-1}$ as an $\mathrm{O}-\mathrm{H}$ bond, whereas the $\mathrm{N}-\mathrm{H}$ bond peak at $3420 \mathrm{~cm}^{-1}$ disappeared. This result indicates that the $\mathrm{HCrO}_{4}{ }^{-}$and $\mathrm{N}-\mathrm{H}$ bonds of ASBC were chemically adsorbed [27].

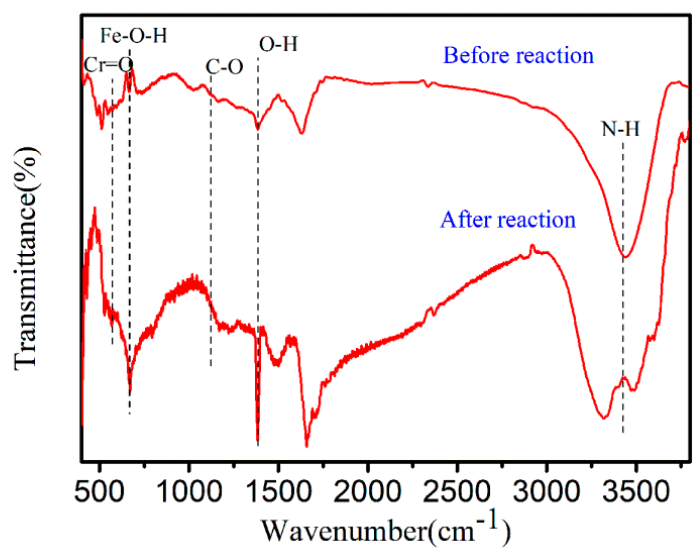

Figure 5. FTIR pattern before and after Cr was removed by nZVI-ASBC. 


\subsection{Adsorption Isotherms and Thermodynamic Study}

The adsorption isotherm equation was used to study the removal of $\mathrm{Cr}(\mathrm{VI})$, and from the fitting results, the Langmuir isotherm adsorption model was considered to be the best model for fitting. Two common adsorption isotherm models (Langmuir and Freundlich) were adopted in this study. The Langmuir and Freundlich isotherm adsorption models are described as Equations (3) and (4), respectively:

$$
\begin{gathered}
\frac{C_{e}}{q_{e} K_{L}}=\frac{1}{q_{m} K_{L}}+\frac{C_{e}}{q_{m}} \\
\lg _{e}=\lg k_{f}+\frac{1}{n} \lg C_{e},
\end{gathered}
$$

where $c_{e}\left(\mathrm{mg} \mathrm{L}^{-1}\right)$ is the equilibrium concentration, $\mathrm{q}_{\mathrm{e}}\left(\mathrm{mg} \mathrm{g}^{-1}\right)$ is the adsorbed amount at equilibrium, $\mathrm{q}_{\mathrm{m}}\left(\mathrm{mg} \mathrm{g}^{-1}\right)$ is the maximum adsorption capacity, $\mathrm{b}\left(\mathrm{L} \cdot \mathrm{mg}^{-1}\right)$ is the adsorption equilibrium constant of the Langmuir model, $\mathrm{k}_{\mathrm{f}}$ is the Freundlich sorption constant, and $\mathrm{n}$ is the Freundlich exponent related to adsorption intensity. Analysis of Figure 6 showed that the $\mathrm{R}^{2}$ of the Langmuir adsorption isotherm was closer to 1 and much higher than the correlation coefficient of the Freundlich adsorption isotherm, indicating that the Langmuir isotherm adsorption model can better adapt to the adsorption behavior. The behavior of $\mathrm{Cr}(\mathrm{VI})$ removal by nZVI-ASBC belonged to monolayer adsorption, which is the first type of adsorption. In general, this type of adsorption is considered to be chemisorption. This result is consistent with that of the FTIR analysis.
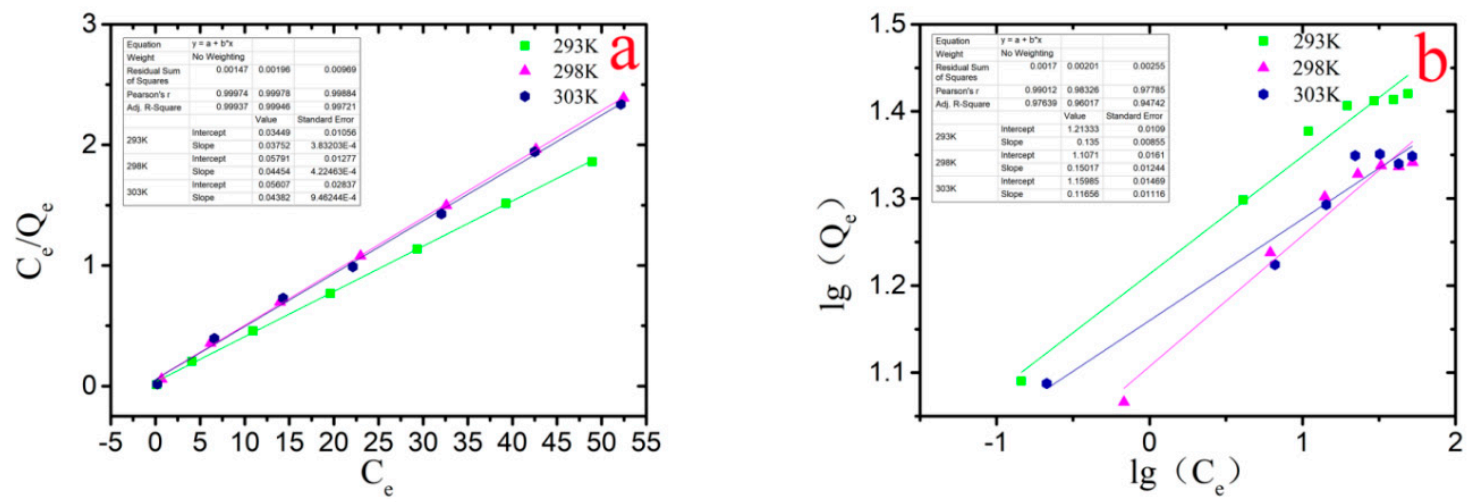

Figure 6. Isothermal adsorption equation fitting at different temperatures (293-303 K): (a) is a fitting of the Langmuir isothermal equation; $(\mathbf{b})$ is a Freundlich isotherm adsorption equation.

The separation factor $\left(R_{L}\right)$ is important in the Langmuir model. $R_{L}$ is generally calculated with the formula:

$$
\mathrm{R}_{\mathrm{L}}=\frac{1}{1+\mathrm{C}_{0} \mathrm{~K}_{\mathrm{L}}}
$$

where $\mathrm{K}_{\mathrm{L}}$ is the isothermal adsorption constant of Langmuir and $\mathrm{C}_{0}\left(\mathrm{mg} \mathrm{L}^{-1}\right)$ is the initial concentration of $\mathrm{Cr}(\mathrm{VI})$ of the adsorbent in the solution before the reaction. The adsorption trend can be determined by the $\mathrm{R}_{\mathrm{L}}$ value. When $\mathrm{R}_{\mathrm{L}}=0$, the isothermal adsorption is irreversible. Meanwhile, $0<\mathrm{R}_{\mathrm{L}}<1$ is advantageous for isothermal adsorption; the smaller the value is, the more favorable it is for isothermal adsorption. When $\mathrm{R}_{\mathrm{L}}=1$, the isothermal adsorption is linear. $\mathrm{R}_{\mathrm{L}}>1$ is not conducive to isothermal adsorption [28]. Table 1 indicates that due to Langmuir isotherm adsorption model fitting, $0<R_{L}<1$ in the process of $\mathrm{Cr}(\mathrm{VI})$ removal by $\mathrm{nZVI}-\mathrm{ASBC}$ at three different temperatures, and the value of $\mathrm{R}_{\mathrm{L}}$ was very close to zero. This result indicates that the adsorption reaction was favorable, and a strong relationship existed between the adsorbent and adsorbate. 
Table 1. Detailed parameters of isothermal adsorption fitting.

\begin{tabular}{ccccc}
\hline Isothermal Adsorption Model & \multicolumn{3}{c}{ Isothermal Parameter } \\
\hline & Temperature (K) & $\mathrm{K}_{\mathrm{L}}(\mathrm{L}$ & $\mathrm{R}_{\mathrm{L}}$ & $\mathrm{R}^{2}$ \\
Langmuir isotherm model & 293 & 1.0873 & 0.0011 & 0.9994 \\
& 298 & 0.7691 & 0.0016 & 0.9995 \\
& 303 & 0.7815 & 0.0016 & 0.9972 \\
\hline & Temperature (K) & $\mathrm{K}_{\mathrm{F}}$ & & $\mathrm{R}^{2}$ \\
& 293 & 16.3418 & & 0.9764 \\
Freundlich isotherm model & 298 & 12.7968 & & 0.9602 \\
& 303 & 14.4494 & & 0.9474 \\
\hline
\end{tabular}

Thermodynamic analysis showed that the removal process was a spontaneous exothermic reaction under low-temperature $(\mathrm{T}<317 \mathrm{~K})$ conditions. The spontaneous nature of the reaction can be judged by analyzing the thermodynamic parameters, including the Gibbs free energy change $(\triangle \mathrm{G})$, enthalpy change $(\triangle H)$, and entropy change $(\triangle S)$. The thermodynamic parameters were calculated by using the formulas:

$$
\begin{gathered}
\Delta \mathrm{G}=-\mathrm{RT} \ln \mathrm{K}_{\mathrm{c}}, \\
\mathrm{K}_{\mathrm{c}}=\frac{\mathrm{q}_{\mathrm{e}}}{\mathrm{C}_{\mathrm{e}}}, \\
\Delta \mathrm{G}=\Delta \mathrm{H}-\mathrm{T} \Delta \mathrm{S},
\end{gathered}
$$

where $\mathrm{R}\left(8.3140 \mathrm{~J} \cdot \mathrm{mol}^{-1} \cdot \mathrm{K}^{-1}\right)$ is the ideal gas constant, $\mathrm{T}(\mathrm{K})$ is the temperature, and $\mathrm{Kc}$ is the equilibrium constant. The calculation results are shown in Table 2 . All negative $\Delta \mathrm{G}$ values meant that the reaction was a spontaneous one. The negative $\Delta \mathrm{H}$ indicated that the adsorption process was an exothermic reaction. Table 2 shows that $\Delta \mathrm{H}$ and $\Delta \mathrm{S}$ were negative, indicating that the reaction was spontaneous at a low temperature $(\mathrm{T}<317 \mathrm{~K})$. The reaction can be carried out spontaneously at a normal temperature,

\begin{tabular}{|c|c|c|c|}
\hline $\mathrm{T}(\mathrm{K})$ & $\Delta \mathrm{G}\left(\mathrm{KJ} \cdot \mathrm{mol}^{-1}\right)$ & $\Delta \mathrm{H}\left(\mathrm{KJ} \cdot \mathrm{mol}^{-1}\right)$ & $\triangle \mathrm{S}\left(\mathrm{KJ} \cdot \mathrm{mol}^{-1} \mathrm{~K}^{-1}\right)$ \\
\hline 293 & -3.8512 & -47.7670 & -0.1505 \\
\hline 298 & -2.5564 & & \\
\hline 303 & -2.3462 & & \\
\hline
\end{tabular}
which is beneficial to the application of nZVI-ASBC in actual $\mathrm{Cr}(\mathrm{VI})$ polluted wastewater.

Table 2. Parameters for thermodynamic study of the adsorption of $\mathrm{Cr}$ onto nZVI-ASBC.

The equivalent adsorption heat $\left(\mathrm{Q}_{\mathrm{ST}}\right)$ was used to determine adsorption energetics, which was equal to enthalpy but with a negative sign $\left(\mathrm{Q}_{\mathrm{ST}}=-\Delta \mathrm{H}\right)$. Generally, the heat of chemical adsorption is between 40 and $600 \mathrm{KJ} \mathrm{mol}^{-1}$. In this study, the equivalent adsorption heat $\left(\mathrm{Q}_{\mathrm{ST}}=47.7670 \mathrm{KJ}\right.$ $\mathrm{mol}^{-1}$ ) was calculated using the formula. Therefore, the adsorption process was chemically driven [29], thereby confirming the previous speculation for chemical adsorption.

\subsection{Kinetics of $\operatorname{Cr}(V I)$ Removal}

Four kinetic models were used to study the rate at which $\mathrm{Cr}(\mathrm{VI})$ was removed by nZVI-ASBC. All reactions were performed under the conditions of $\mathrm{pH}=5$, temperature $298 \mathrm{~K}$, and initial concentration Cr $10 \mathrm{mg} \mathrm{L}^{-1}$. First-order (Equation (9)) and second-order (Equation (10)) kinetics are expressed as:

$$
\begin{aligned}
\ln C & =-k_{1} t+\ln C_{0}, \\
\frac{1}{C} & =k_{2} t+\frac{1}{C_{0}},
\end{aligned}
$$


where $\mathrm{C}$ is the concentration of $\mathrm{Cr}(\mathrm{VI})$ at time $t, \mathrm{C}_{0}$ is the initial concentration of $\mathrm{Cr}(\mathrm{VI}), \mathrm{t}(\mathrm{min})$ is the reaction time, $\mathrm{k}_{1}$ is the first-order reaction rate, and $\mathrm{k}_{2}$ is the second-order reaction rate.

The pseudo first order (Equation (11)) and pseudo second order (Equation (12)) are described as:

$$
\begin{gathered}
\ln \left(\mathrm{q}_{\mathrm{e}}-\mathrm{q}_{\mathrm{t}}\right)=-\mathrm{k}_{1}^{\prime} \mathrm{t}+\ln \mathrm{q}_{\mathrm{e}^{\prime}} \\
\frac{\mathrm{t}}{\mathrm{q}_{\mathrm{t}}}=\frac{1}{\mathrm{k}_{2}^{\prime} \mathrm{q}_{\mathrm{e}}^{2}}+\frac{\mathrm{t}}{\mathrm{q}_{\mathrm{e}}},
\end{gathered}
$$

where $\mathrm{k}_{1}{ }^{\prime}$ is the adsorption rate constant of the pseudo first order and $\mathrm{k}_{2}{ }^{\prime}$ is the adsorption rate constant of the pseudo second order.

The fitting results in Table 3 show that the pseudo second order has a good fitting effect. When the initial concentration of $\mathrm{Cr}$ is $10 \mathrm{mg} \mathrm{L}^{-1}, \mathrm{pH}=5$, and the dosage is $0.08 \mathrm{~g}$, the kinetic experiment was carried out. Table 3 indicates that the $\mathrm{R}^{2}$ of the pseudo second-order dynamics fit is 0.9998 , which is more reliable than other kinetics. The $\mathrm{q}_{\mathrm{e}}$ predicted by this model is $24.1564 \mathrm{mg}^{\mathrm{g}} \mathrm{g}^{-1}$, which is consistent with the experimental result of $23.9250 \mathrm{mg} \cdot \mathrm{g}^{-1}$. Therefore, the removal of $\mathrm{Cr}(\mathrm{VI})$ by nZVI-ASBC is in accordance with the pseudo second-order dynamic model. The removal yield of $\mathrm{Cr}(\mathrm{VI})$ by nZVI-ASBC depends on the concentrations of $\mathrm{Cr}$ ions and the adsorbent [30]. Moreover, $\mathrm{k}$ $=0.1544$ can be obtained, which indicates that the reaction rate of the adsorption was $0.5365 \mathrm{mg} \cdot \mathrm{g}^{-1}$ min $^{-1}$ by calculation. This result means that the nZVI modified by ASBC has a high removal yield.

Table 3. Kinetic parameters of $\mathrm{Cr}(\mathrm{VI})$ removal by nZVI-ASBC.

\begin{tabular}{cccc}
\hline & $\mathbf{k}$ & R-Square & $\mathbf{C}_{\mathbf{0}}$ \\
\hline First order & -0.1605 & 0.6662 & 1.2628 \\
Second order & 1.2745 & 0.6092 & 1.2747 \\
\hline kseudo first order & -0.2062 & R-square & $\mathbf{q}_{\mathbf{e}}$ \\
\hline Pseudo second order & 0.1544 & 0.6756 & 3.1970 \\
\hline
\end{tabular}

\subsection{Possible Mechanisms}

In this work, the mechanisms of $\mathrm{Cr}(\mathrm{VI})$ removal were considered to be adsorption and reduction. After the reaction, as shown in Figure 2d, Cr was detected on nZVI-ASBC by EDS, indicating that some of the $\mathrm{Cr}$ was adsorbed on the adsorbent after the reaction. Adsorption isotherms and thermodynamic studies were used for analysis, and the reaction was determined to be chemical adsorption. The specific details of chemisorption were further investigated by FTIR analysis. As shown in Figure 5, the peaks of the $\mathrm{Cr}=\mathrm{O}$ and $\mathrm{O}-\mathrm{H}$ functional groups appeared after the reaction, and the peak of the $\mathrm{N}-\mathrm{H}$ functional group disappeared because the N-H functional group bound with $\mathrm{HCrO}_{4}^{-}$. As suggested in Figure 7, the $\mathrm{N}-\mathrm{H}$ functional group first reacted with $\mathrm{H}^{+}$and then with -O-Cr. The comparison of the removal of $\mathrm{Cr}(\mathrm{VI})$ by nZVI-ASBC and ASBC in Figure 1e reveals that the removal yield of $\mathrm{Cr}(\mathrm{VI})$ by ASBC only accounted for $14.86 \%$ of the removal yield of $\mathrm{Cr}(\mathrm{VI})$ by nZVI-ASBC. On this basis, we determined that the removal process mainly relied on reduction and adsorption. However, as shown in Figure 1a, adsorption had a significant effect on the initial removal speed not only because low $\mathrm{pH}$ favored the redox reaction of $\mathrm{nZVI}$ and $\mathrm{Cr}(\mathrm{VI})$ but also because low $\mathrm{pH}$ facilitated the bonding of $\mathrm{Cr}$ and $\mathrm{N}-\mathrm{H}$ functional groups. 

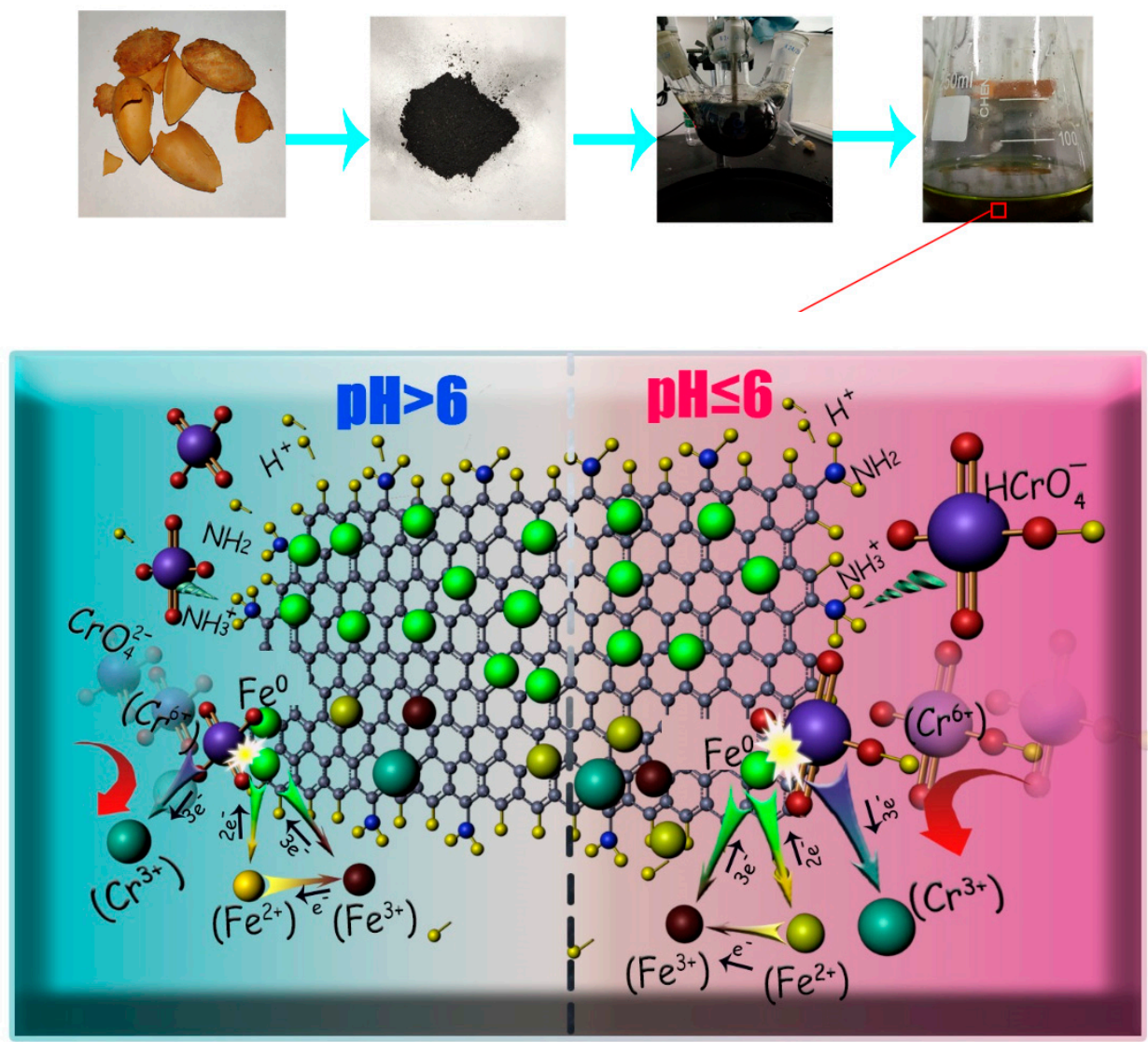

Figure 7. Possible mechanism of Cr removal by nZVI-ASBC.

In summary, Figure 7 suggested that when $\mathrm{pH} \leq 6$, chemisorption and reduction were observed in the reaction. The presence of chemisorption promoted the rapid progress of reduction, thus allowing the reaction to reach equilibrium quickly. When $\mathrm{pH}>6$, the rates of adsorption and redox reactions were slow due to the low $\mathrm{H}^{+}$content [19]. Moreover, the low $\mathrm{H}^{+}$concentration was not conducive to the adsorption of $\mathrm{CrO}_{4}{ }^{2-}$ by ASBC.

\section{Conclusions}

ASBC modified with nZVI had a significant effect on the removal of $\mathrm{Cr}(\mathrm{VI})$. The experiments showed that the removal yield of $\mathrm{Cr}(\mathrm{VI})$ was the best in $293 \mathrm{~K}$ and low-pH conditions. nZVI-ASBC efficiently removed $\mathrm{Cr}(\mathrm{VI})$ as a spontaneous reaction at low temperatures. Approximately $90 \%$ of $\mathrm{Cr}(\mathrm{VI})$ was removed by nZVI-ASBC within $60 \mathrm{~min}$. The removal of $\mathrm{Cr}(\mathrm{VI})$ was governed by the reduction by nZVI and the chemical adsorption of ASBC. nZVI-ASBC has a great potential for use as a synthetic material for $\mathrm{Cr}(\mathrm{VI})$ removal.

Author Contributions: Writing-original draft, Y.S. (Yaorong Shu), D.G.; Formal analysis, Y.S. (Yuting Shi); Software, J.W.; Supervision, B.J.; Funding acquisition, M.H.; Formal analysis, S.L.; Writing-review \& editing, B.C., M.H., D.G. All authors have read and agreed to the published version of the manuscript.

Funding: This research was funded by the National Natural Science Foundation of China $(21706087,51808241)$, project of the Guangdong Provincial Key Laboratory of Development and Comprehensive Utilization of Mineral Resources (2017B030314046), and Qingdao Science and Technology Program (17-3-3-77-nsh).

Acknowledgments: Authors would also like to thank the Analytical and Test Center of HUST for carrying out the analysis of the samples.

Conflicts of Interest: The authors declare no conflict of interest. 


\section{References}

1. Kazemi, M.; Jahanshahi, M.; Peyravi, M. Hexavalent chromium removal by multilayer membrane assisted by photocatalytic couple nanoparticle from both permeate and retentate. J. Hazard. Mater. 2018, 344, 12-22. [CrossRef]

2. Sharma, A.K.; Devan, R.S.; Arora, M.; Kumar, R.; Ma, Y.; Babu, J.N. Reductive-co-precipitated cellulose immobilized zerovalent iron nanoparticles in ionic liquid/water for $\mathrm{Cr}(\mathrm{VI})$ adsorption. Cellulose 2018, 25, 5259-5275. [CrossRef]

3. Zhang, X.; Fu, W.; Yin, Y.; Chen, Z.; Qiu, R.; Simonnot, M.; Wang, X. Adsorption-reduction removal of Cr(VI) by tobacco petiole pyrolytic biochar: Batch experiment, kinetic and mechanism studies. Bioresour. Technol. 2018, 268, 149-157. [CrossRef]

4. Zhang, X.; Lv, L.; Qin, Y.; Xu, M.; Jia, X.; Chen, Z. Removal of aqueous Cr(VI) by a magnetic biochar derived from Melia azedarach wood. Bioresour. Technol. 2018, 256, 1-10. [CrossRef]

5. Yang, P.; Guo, D.; Chen, Z.; Cui, B.; Xiao, B.; Liu, S.; Hu, M. Removal of Cr (VI) from aqueous solution using magnetic biochar synthesized by a single step method. J. Disper. Sci. Technol. 2017, 38, 1665-1674. [CrossRef]

6. Li, X.; Liu, Y.; Hao, J.; Wang, W. Study of Almond Shell Characteristics. Materials 2018, 11, 1782. [CrossRef]

7. Simeonidis, K.; Mourdikoudis, S.; Kaprara, E.; Mitrakas, M.; Polavarapu, L. Inorganic engineered nanoparticles in drinking water treatment: A critical review. Environ. Sci. Water Res. Technol. 2016, 2, 43-70. [CrossRef]

8. Huang, Y.; Zhang, W.; Zhang, M.; Zhang, X.; Zhao, Y. Hydroxyl-functionalized TiO 2 @SiO 2 @Ni/nZVI nanocomposites fabrication, characterization and enhanced simultaneous visible light photocatalytic oxidation and adsorption of arsenite. Chem. Eng. J. 2018, 338, 369-382. [CrossRef]

9. Jiang, D.; Huang, D.; Lai, C.; Xu, P.; Zeng, G.; Wan, J.; Tang, L.; Dong, H.; Huang, B.; Hu, T. Difunctional chitosan-stabilized $\mathrm{Fe} / \mathrm{Cu}$ bimetallic nanoparticles for removal of hexavalent chromium wastewater. Sci. Total. Environ. 2018, 644, 1181-1189. [CrossRef]

10. Dalal, U.; Reddy, S.N. A novel nano zero-valent iron biomaterial for chromium (Cr6+ to Cr3+) reduction. Environ. Sci. Pollut. Res. 2019, 26, 10631-10640. [CrossRef]

11. Zhang, M.; Li, J.; Wang, Y. Impact of biochar-supported zerovalent iron nanocomposite on the anaerobic digestion of sewage sludge. Environ. Sci. Pollut. Res. 2019, 26, 10292-10305. [CrossRef]

12. Huang, X.; Ling, L.; Zhang, W. Nanoencapsulation of hexavalent chromium with nanoscale zero-valent iron: High resolution chemical mapping of the passivation layer. J. Environ. Sci. China 2018, 67, 4-13. [CrossRef]

13. Zhu, N.; Xu, Y.; Dai, L.; Zhang, Y.; Hu, G. Application of sequential extraction analysis to Pb(II) recovery by zerovalent iron-based particles. J. Hazard. Mater. 2018, 351, 138-146. [CrossRef]

14. Wang, X.; Wang, T.; Ma, J.; Liu, H.; Ning, P. Synthesis and characterization of a new hydrophilic boehmite-PVB/PVDF blended membrane supported nano zero-valent iron for removal of $\mathrm{Cr}(\mathrm{VI})$. Sep. Purif. Technol. 2018, 205, 74-83. [CrossRef]

15. Qian, L.; Zhang, W.; Yan, J.; Han, L.; Chen, Y.; Ouyang, D.; Chen, M. Nanoscale zero-valent iron supported by biochars produced at different temperatures: Synthesis mechanism and effect on $\mathrm{Cr}(\mathrm{VI})$ removal. Environ. Pollut. 2017, 223, 153-160. [CrossRef]

16. Wu, B.; Peng, D.; Hou, S.; Tang, B.; Wang, C.; Xu, H. Dynamic study of Cr(VI) removal performance and mechanism from water using multilayer material coated nanoscale zerovalent iron. Environ. Pollut. 2018, 240, 717-724. [CrossRef]

17. Pradhan, D.; Sukla, L.B.; Sawyer, M.; Rahman, P.K.S.M. Recent bioreduction of hexavalent chromium in wastewater treatment: A review. J. Ind. Eng. Chem. 2017, 55, 1-20. [CrossRef]

18. Huang, T.; Liu, L.; Zhou, L.; Zhang, S. Electrokinetic removal of chromium from chromite ore-processing residue using graphite particle-supported nanoscale zero-valent iron as the three-dimensional electrode. Chem. Eng. J. 2018, 350, 1022-1034. [CrossRef]

19. Dong, H.; Deng, J.; Xie, Y.; Zhang, C.; Jiang, Z.; Cheng, Y.; Hou, K.; Zeng, G. Stabilization of nanoscale zero-valent iron (nZVI) with modified biochar for $\mathrm{Cr}(\mathrm{VI})$ removal from aqueous solution. J. Hazard. Mater. 2017, 332, 79-86. [CrossRef]

20. Li, Y.; Li, X.; Han, D.; Huang, W.; Yang, C. New insights into the role of Ni loading on the surface structure and the reactivity of nZVI toward tetrabromo- and tetrachlorobisphenol A. Chem. Eng. J. 2017, 311, 173-182. [CrossRef] 
21. Yang, F.; Zhang, S.; Sun, Y.; Cheng, K.; Li, J.; Tsang, D.C.W. Fabrication and characterization of hydrophilic corn stalk biochar-supported nanoscale zero-valent iron composites for efficient metal removal. Bioresour. Technol. 2018, 265, 490-497. [CrossRef]

22. Su, H.; Fang, Z.; Tsang, P.E.; Fang, J.; Zhao, D. Stabilisation of nanoscale zero-valent iron with biochar for enhanced transport and in-situ remediation of hexavalent chromium in soil. Environ. Pollut. 2016, 214, 94-100. [CrossRef]

23. Shang, J.; Zong, M.; Yu, Y.; Kong, X.; Du, Q.; Liao, Q. Removal of chromium (VI) from water using nanoscale zerovalent iron particles supported on herb-residue biochar. J. Environ. Manag. 2017, 197, 331-337. [CrossRef]

24. Dai, Y.; Hu, Y.; Jiang, B.; Zou, J.; Tian, G.; Fu, H. Carbothermal synthesis of ordered mesoporous carbon-supported nano zero-valent iron with enhanced stability and activity for hexavalent chromium reduction. J. Hazard. Mater. 2016, 309, 249-258. [CrossRef]

25. Zeng, G.; Liu, Y.; Tang, L.; Yang, G.; Pang, Y.; Zhang, Y.; Zhou, Y.; Li, Z.; Li, M.; Lai, M.; et al. Enhancement of Cd(II) adsorption by polyacrylic acid modified magnetic mesoporous carbon. Chem. Eng. J. 2015, 259, 153-160. [CrossRef]

26. Yan, J.; Han, L.; Gao, W.; Xue, S.; Chen, M. Biochar supported nanoscale zerovalent iron composite used as persulfate activator for removing trichloroethylene. Bioresour. Technol. 2015, 175, 269-274. [CrossRef]

27. Mohamed, A.; Osman, T.A.; Toprak, M.S.; Muhammed, M.; Yilmaz, E.; Uheida, A. Visible light photocatalytic reduction of $\mathrm{Cr}(\mathrm{VI})$ by surface modified $\mathrm{CNT} /$ titanium dioxide composites nanofibers. J. Mol. Catal. A Chem. 2016, 424, 45-53. [CrossRef]

28. Ma, H.; Yang, J.; Gao, X.; Liu, Z.; Liu, X.; Xu, Z. Removal of chromium (VI) from water by porous carbon derived from corn straw: Influencing factors, regeneration and mechanism. J. Hazard. Mater. 2019, 369, 550-560. [CrossRef]

29. Chen, L.; Zuo, L.; Jiang, Z.; Jiang, S.; Liu, K.; Tan, J.; Zhang, L. Mechanisms of shale gas adsorption: Evidence from thermodynamics and kinetics study of methane adsorption on shale. Chem. Eng. J. 2019, 361, 559-570. [CrossRef]

30. Mortazavian, S.; An, H.; Chun, D.; Moon, J. Activated carbon impregnated by zero-valent iron nanoparticles (AC/nZVI) optimized for simultaneous adsorption and reduction of aqueous hexavalent chromium: Material characterizations and kinetic studies. Chem. Eng. J. 2018, 353, 781-795. [CrossRef] 